\title{
Greek Private Dentists: Relationship with Patients and Professional Challenges
}

\author{
Vlasiadis $\mathbf{K}^{1 *}$, Samaritaki $\mathbf{E}^{2}$, Koutsamani $\mathbf{M}^{3}$, Tsiligianni $\mathbf{I}^{4}$, Tzoutzas $\mathbf{I}^{5}$ \\ ${ }^{1}$ Director Dentist, Dental Clinic, Scientific Collaborator, Health Planning Unit, School of Medicine, University Hospital of Crete, Greece, Greece \\ ${ }^{2}$ Register Nurse, Cardiosurgical Unit, University General Hospital, Greece \\ ${ }^{3}$ Consultant Dentist, Venizeleio Hospital of Heraklion, Knossos Street, Greece
}

${ }^{4}$ Assistant Professor in Social Medicine, Health Planning Unit, Department of Social Medicine, University of Crete, School of Medicine, Voutes, Greece ${ }^{5}$ Professor of Dental Practice Management University of Athens School of Dentistry, Greece

Submission: April 13, 2020; Published: April 20, 2020

*Corresponding author: Konstantinos Vlasiadis, Director Dentist, Dental Clinic, Scientific Collaborator, Laboratory of Health Planning, School of Medicine, University Hospital of Crete, Greece

Abstract

Objective: To evaluate the relationship between private dentists and patients and depict the major challenges this professional group face.

Materials-Methods: It was a cross-sectional study, with a sample of 281 private dentists from the region of Heraklion, Crete. The data was collected using an anonymous, self-administered questionnaire of Greek origin, previously tested in practice.

Results: The relationship between dentists and patients was examined. $55.1 \%$ of the respondents considered that their patients trust them and $61.4 \%$ that there is cooperation. Some of the dentist's major challenges, from the patient's side, were delays in scheduled appointments (56\%), complaints about high dental care costs $(48.9 \%)$ and unwillingness to follow the instructions (51.3\%). Statistically significant variations were communication with the patients $(\mathrm{p}=0.009)$ and administrative procedures $(\mathrm{p}=0.011)$, depending on the gender $(\mathrm{p}=0.011)$, the age $(\mathrm{p}=0.001)$, the training level $(\mathrm{p}=0.002)$ and whether dentists were practicing in an urban or a rural area $(\mathrm{p}=0.006)$.

Conclusion: Dentists seemed to be satisfied with their relationship with their patients and their profession. They were concerned about appointments, dental costs and noncompliance with given instructions. Administrative procedures seemed to bother younger dentists. Further research is required to determine whether the general financial conditions in a country affects this particular professional group, what do patients believe about dentists with respect to age, gender and education of both groups.

Keywords: Dentist; Job satisfaction; Communication; Dental patient; Expectations

\section{Introduction}

Nowadays the increase in demand due to population ageing, the professional autonomy level, the good relationship among colleagues, the existence of free time and the satisfied remuneration, make dentistry an attractive profession [1-5]. Nevertheless, few studies have addressed the issue of everyday problems-difficulties dentists are called upon to face, which, as a result, have an impact on the level of satisfaction they draw from their profession [6] and are associated with the gender, the age and the interaction between dentists and patients [7]. For example, professional autonomy seems to satisfy more male dentists who are interested in owning a business [4]. In contrary women seem to draw satisfaction from their potential to develop their professional skills [8-10]. Younger dentists seem to have little free time while they are concerned with the management of their dental practice $[9,10]$. Older professionals seem to be more satisfied by their occupation [10]. The area where dentists are practicing, urban or rural, affects the level of satisfaction they get from their profession. Dentists working in non-urban areas are concerned about the lack of recognition by their social environment, while they are contented with the fact that they have more free time. Dentists in urban centers are more satisfied with their relationships with their colleagues $[1,10]$.

Thus, it is obvious that the professional satisfaction of dentists depends on a wide variety of $\mathrm{f}$ actors that needs to be examined 
[11]. The objective of the present study was to evaluate the relationship between dentists and patients and detect the major problems this particular professional group is concerned with.

\section{Materials \& Methods}

This was a cross sectional observational study. The sample included 298 private dentists from the municipality of Heraklion, Crete. From them 281 participated at the end. The tool used for the collection of data was the "Dentist's Questionnaire" by Demetriadis et al. [12]. Permission to use the particular questionnaire has been granted by its creators. The questionnaire includes four sections (40 statements) which dentists were asked to agree or disagree on and, also, select the most common difficulties they encounter and how often. The statements appear in the form of a 4-point Likert scale with values ranging from 0 to 4 (0: Undecided, 1: Strongly disagree, 2: Disagree, 3: Agree, 4: Strongly agree).The researcher visited the dental practices to distribute the questionnaire and inform the dentists about the research. The questionnaires were accompanied by a note informing the prospective participants on the topic of the research and assuring them of the anonymity of the answers. In addition, written informed consent was received. The collection of the questionnaires was performed by the researcher after 10 days from the day the questionnaires were distributed. Permission to perform the research was provided by the Bioethics Committee of the University of Crete (Protocol No: 15/25-5-2015).

\section{Statistical Methods}

The analysis was performed using the statistical software IBM SPSS Statistics 24.0. The questions-variables related to the demographic and professional characteristics of the participants were expressed as frequencies, percentages. The age, any previous work experience and the working hours were expressed using the mean value and standard deviation. The responses were categorized in the form of quality ordinal variables. The questions were also expressed in frequencies and frequencies, percentages and coded 2-valued scales (Disagree and Agree). Pearson $\chi 2$ test was used to describe the effect of discrete variables.

\section{Results}

The questionnaires were completed by 281 dentists practicing in the prefecture of Heraklion, Crete. $57.3 \%$ of the sample were men and $86.1 \%$ worked in an urban area. The participants' mean age was $47.2 \pm 9.5$ years and as regards age distribution the most common group was $36-45$ years $(33.5 \%) .98 .2 \%$ of the respondents owned a dental practice while $1.5 \%$ did not work independently. $36.7 \%$ had previous working experience $10-20$ years and the average work experience was $18.5 \pm 9.6$ years. The dentists providing answers more frequently belonged in the groups working 40-49 (37.7\%) and 30-39(32.4\%) hours per week. The average time of working hours was found to be $36.0 \pm 11.3$. As regards dentists' training, $18.1 \%$ had a master's degree,
$2.8 \%$ a $\mathrm{PhD}$ and $10.3 \%$ had obtained a dental subspecialty. The most common dental specialties were periodontology (25.9\%), prosthetics (22.4\%) and orthodontics (15.3\%).

Responses to the statements in the questionnaire per question group

\section{Dentists' attitudes-behaviors towards their patients}

Among the dentists who took part in the research, 58.6\% agreed that they should explain to their patients in detail what kind of treatment they are going to receive, $68.2 \%$ how dental problems could be prevented and $48.9 \%$ that they should answer their patients' questions. $45.2 \%$ believed that patients should not be pushed to follow their instructions, $71.7 \%$ that patients should seek a second opinion and $59.8 \%$ stated that patients must pay their dentist even if they are not satisfied. .0 50\% believed that dentists should not ask questions about their patients' personal life and $68.8 \%$ stated that they should show some concern about their patients' financial problems.

\section{Patients' attitudes-behaviors towards dentists}

Almost all the questions in this group had a maximum frequency in the choice "Agree" at percentages ranging from $49.3 \%-64.2 \%$. The only exception was the question about whether patients should comment on the dentist's work during treatment on which $38.4 \%$ disagreed. Furthermore, $45.8 \%$ disagreed on the statement according to which patients should inform the dentist when they are not satisfied with the treatment.

\section{Difficulties dentists encounter as regards their patients}

Dentists' views on their relationship with patients varied. More specifically, $55.1 \%$ of the respondents considered that their patients trust them and $61.4 \%$ that there was cooperation between dentists and patients. $48.0 \%$ didn't feel that their patients question the treatment plan suggested, $47.7 \%$ felt that patients appreciate the dentist's work and $48.9 \%$ of the dentists didn't believe that an inaccurate medical history hinders everyday clinical practice. Finally, $51.3 \%$ agreed that failure to follow the instructions is a common problem along with complaints about dental care costs (48.9\%), the delay or cancellation of appointments (43.2\%) and the inability to meet financial obligations (39.3\%).

\section{General difficulties-everyday professional issues}

Concerning the difficulties dentists encountered in their working place in relation to the management of the dental practice and their personal, family and professional status, $8.5 \%$ did not provide any answers. $52.9 \%$ of the respondents stated that they rarely feel low acceptance by their social background and $45.5 \%$ loneliness-alienation. $36.5 \%$ often dealed with financial difficulties, $43.7 \%$ felt exhaustion at the end of the day and $47.0 \%$ felt that they have little free time. 
Difficulties dentists encounter in everyday dental practice with respect to gender, training level, work area and working hours

Differentiation as regards the gender was noted in the statement according to which patients should not pay the dentist when they are not satisfied with the treatment, on which male dentists agreed at a higher percentage $(19.4 \%)$ than female dentists $(8.1 \% \mathrm{p}=0.011)$. In addition, $69.4 \%$ of men agreed that one of the most common difficulties dentists encounter is patients' unwillingness to comply with the instructions or advice provided while the percentage for women reached $54.6 \%$ $(p=0.012)$. The age seemed to cause statistical differences for quite a few of the statements of the questionnaire appearing in the form of agreement or disagreement. The older the dentists get, the more they seem to agree that patients should not seek a second opinion about the suggested treatment. The percentage of agreement at the age of 56 and above reaches $16.1 \%(p=0.016)$. For the statement according to which patients should inform the dentist when they are dissatisfied with the treatment, the lowest percentage of agreement appeared in the age group 36-45 years (13.1\%, p=0.001).Younger professionals, <35 years, seemed to agree that patients often complain about their previous dentists (90.9\%, $\mathrm{p}=0.009)$, comment on the dental work during treatment (65.6\%, $\mathrm{p}=0.021)$, express their discontent when dissatisfied with the treatment $(96.9 \%, \mathrm{p}=0.021)$ and choose a dentist based on financial criteria $(\mathrm{p}<0.001)$ (Table 1$)$.

Table 1: Differentiation in the percentages of agreement/disagreement on statements Q12 per age group.

\begin{tabular}{|c|c|c|c|c|c|c|c|c|c|c|c|}
\hline \multicolumn{12}{|c|}{ Age group } \\
\hline \multirow{2}{*}{\multicolumn{2}{|c|}{$\mathrm{N}$}} & \multirow{3}{*}{$\begin{array}{c}\text { Total } \\
\mathbf{n} \\
31\end{array}$} & \multicolumn{2}{|c|}{$<=35$} & \multicolumn{2}{|c|}{$36-45$} & \multicolumn{2}{|c|}{ 46-55 } & \multicolumn{2}{|c|}{$56+$} & \multirow[b]{2}{*}{ p } \\
\hline & & & $\%$ & $\mathbf{n}$ & $\%$ & n & $\%$ & $\mathbf{n}$ & $\%$ & & \\
\hline \multirow[t]{2}{*}{ Q12_1 } & Disagree & & 1 & 3.0 & 9 & 9.8 & 10 & 10.9 & 11 & 17.7 & 0.164 \\
\hline & Agree & 248 & 32 & 97.0 & 83 & 90.2 & 82 & 89.1 & 51 & 82.3 & \\
\hline \multirow[t]{2}{*}{ Q12_2 } & Disagree & 64 & 3 & 9.1 & 19 & 20.4 & 19 & 20.9 & 23 & 37.7 & 0.009 \\
\hline & Agree & 214 & 30 & 90.9 & 74 & 79.6 & 72 & 79.1 & 38 & 62.3 & \\
\hline \multirow[t]{2}{*}{ Q12_3 } & Disagree & 142 & 11 & 34.4 & 43 & 47.3 & 47 & 51.6 & 41 & 66.1 & 0.021 \\
\hline & Agree & 134 & 21 & 65.6 & 48 & 52.7 & 44 & 48.4 & 21 & 33.9 & \\
\hline \multirow[t]{2}{*}{ Q12_4 } & Disagree & 188 & 22 & 71.0 & 73 & 86.9 & 56 & 62.2 & 37 & 62.7 & 0.001 \\
\hline & Agree & 76 & 9 & 29.0 & 11 & 13.1 & 34 & 37.8 & 22 & 37.3 & \\
\hline \multirow[t]{2}{*}{ Q12_5 } & Disagree & 91 & 14 & 42.4 & 30 & 31.9 & 33 & 35.9 & 14 & 23.0 & 0.212 \\
\hline & Agree & 189 & 19 & 57.6 & 64 & 68.1 & 59 & 64.1 & 47 & 77.0 & \\
\hline \multirow[t]{2}{*}{ Q12_6 } & Disagree & 24 & 2 & 6.1 & 10 & 10.6 & 9 & 9.9 & 3 & 4.8 & 0.556 \\
\hline & Agree & 256 & 31 & 93.9 & 84 & 89.4 & 82 & 90.1 & 59 & 95.2 & \\
\hline \multirow[t]{2}{*}{ Q12_7 } & Disagree & 50 & 1 & 3.1 & 12 & 13.6 & 17 & 19.3 & 20 & 38.5 & $<0.001$ \\
\hline & Agree & 210 & 31 & 96.9 & 76 & 86.4 & 71 & 80.7 & 32 & 61.5 & \\
\hline \multirow[t]{2}{*}{ Q12_8 } & Disagree & 91 & 9 & 29.0 & 36 & 43.9 & 26 & 31.3 & 20 & 37.0 & 0.301 \\
\hline & Agree & 159 & 22 & 71.0 & 46 & 56.1 & 57 & 68.7 & 34 & 63.0 & \\
\hline
\end{tabular}

Table abbreviations: Q12-1: do patients usually visit you in case of an emergency? Q12-2: do your patients complain about previous doctors? Q12-3: do your patients comment on your work during treatment?Q12-4: do your patients inform you when they are dissatisfied with the treatment? Q12-5: do your patients take responsibility for the condition of their oral health? Q12-6: do your patients ask details about the suggested treatment? Q12-7: do your patients choose a dentist based on the treatment cost?Q12-8: do your patients choose a dentist based on the quality of the dental equipment?

Professionals under 35 years agreed that delays or cancellations of appointments (without prior notice) $(63.6 \%, \mathrm{p}=0.026)$ and complaints about the dental care cost $(72.7 \%, \mathrm{p}=0.047)$ are some of the most common difficulties they deal with in relation to their patients. In almost all statements, no tendency of reduction or increase along the age was noted with the exception of the inaccurate dental and medical history where the highest percentage of agreement was in the age group $<=35$ $(40.6 \%, p=0.040)$. The most severe differences were noted for groups 36-45 or 46-55 years. More specifically, the age group 4655 believed that very often there is a lack of trust $(8.9 \%, \mathrm{p}=0.042)$, non-appreciation of their work $(18.6 \%, \mathrm{p}=0.002)$, inability to manage their financial arrangements with patients $(57.6 \%$, $\mathrm{p}=0.021$ ) and failure to organize and manage their business and their dental practice $(29.3 \%, \mathrm{p}=0.011)$ (Table 2). Dentists with postgraduate studies believed that they should not put pressure on patients to follow their instructions $(48.6 \%, \mathrm{p}<0.010)$. The same applies for the statement according to which patients usually 


\section{Advances in Dentistry \& Oral Health}

visit a dentist in case of an emergency $(\mathrm{p}=0.002)$. They were also facing problems such as delay or cancellation of appointments by the patients (without prior notice) $(56.4 \%, \mathrm{p}=0.035)$, inability to meet financial obligations $(59.3 \%, \mathrm{p}=0.005)$, noncompliance with their instructions or advice $(63.1 \%, \mathrm{p}=0.003)$, doubts about the treatment plan $(93.4 \%, \mathrm{p}=0.046)$, inaccurate dental and medical history $(23.2 \%, \mathrm{p}=0.021)$, failure to manage their financial arrangements with their patients $(45.2 \%, \mathrm{p}=0.017)$, economic distress in general $(45.5 \%, \mathrm{p}=0.001)$ and, finally, inability to attend continuing education programmers $(48.2 \% \mathrm{p}=0.010)$ (Table 3$)$.

Table 2: Differentiation in the percentages of agreement/disagreement on statements Q13 per age group.

\begin{tabular}{|c|c|c|c|c|c|c|c|c|c|c|c|}
\hline \multicolumn{12}{|c|}{ Age group } \\
\hline \multirow{2}{*}{\multicolumn{2}{|c|}{$\mathbf{N}$}} & \multirow{3}{*}{$\begin{array}{c}\text { Total } \\
\mathbf{n} \\
122 \\
\end{array}$} & \multicolumn{2}{|c|}{$<=35$} & \multicolumn{2}{|c|}{$36-45$} & \multicolumn{2}{|c|}{$46-55$} & \multicolumn{2}{|c|}{$56+$} & \multirow{3}{*}{$\begin{array}{c}\mathbf{p} \\
0.026\end{array}$} \\
\hline & & & \multirow{2}{*}{$\begin{array}{l}\% \\
12\end{array}$} & \multirow{2}{*}{$\begin{array}{c}\mathbf{N} \\
36.4\end{array}$} & \multirow{2}{*}{$\begin{array}{l}\% \\
40\end{array}$} & \multirow{2}{*}{$\begin{array}{c}\mathbf{n} \\
42.6\end{array}$} & \multirow{2}{*}{$\begin{array}{l}\% \\
33\end{array}$} & \multirow{2}{*}{$\frac{\mathbf{n}}{36.3}$} & \multirow{2}{*}{$\begin{array}{l}\% \\
37\end{array}$} & \multirow[b]{2}{*}{59.7} & \\
\hline Q13_1 & Disagree & & & & & & & & & & \\
\hline & Agree & 158 & 21 & 63.6 & 54 & 57.4 & 58 & 63.7 & 25 & 40.3 & \\
\hline \multirow[t]{2}{*}{ Q13_2 } & Disagree & 116 & 9 & 27.3 & 43 & 46.2 & 32 & 34.8 & 32 & 51.6 & 0.047 \\
\hline & Agree & 164 & 24 & 72.7 & 50 & 53.8 & 60 & 65.2 & 30 & 48.4 & \\
\hline \multirow[t]{2}{*}{ Q13_3 } & Disagree & 114 & 16 & 48.5 & 42 & 45.2 & 28 & 30.4 & 28 & 45.2 & 0.106 \\
\hline & Agree & 166 & 17 & 51.5 & 51 & 54.8 & 64 & 69.6 & 34 & 54.8 & \\
\hline \multirow[t]{2}{*}{ Q13_4 } & Disagree & 103 & 10 & 30.3 & 41 & 43.6 & 27 & 30.0 & 25 & 40.3 & 0.204 \\
\hline & Agree & 176 & 23 & 69.7 & 53 & 56.4 & 63 & 70.0 & 37 & 59.7 & \\
\hline \multirow[t]{2}{*}{ Q13_5 } & Disagree & 214 & 24 & 72.7 & 73 & 78.5 & 68 & 73.9 & 49 & 79.0 & 0.795 \\
\hline & Agree & 66 & 9 & 27.3 & 20 & 21.5 & 24 & 26.1 & 13 & 21.0 & \\
\hline \multirow[t]{2}{*}{ Q13_6 } & Disagree & 255 & 32 & 97.0 & 84 & 92.3 & 80 & 89.9 & 59 & 98.3 & 0.171 \\
\hline & Agree & 18 & 1 & 3.0 & 7 & 7.7 & 9 & 10.1 & 1 & 1.7 & \\
\hline \multirow[t]{2}{*}{ Q13_7 } & Disagree & 145 & 15 & 45.5 & 51 & 54.3 & 46 & 50.5 & 33 & 53.2 & 0.833 \\
\hline & Agree & 135 & 18 & 54.5 & 43 & 45.7 & 45 & 49.5 & 29 & 46.8 & \\
\hline \multirow[t]{2}{*}{ Q13_8 } & Disagree & 255 & 31 & 100.0 & 85 & 95.5 & 82 & 91.1 & 57 & 100.0 & 0.042 \\
\hline & Agree & 12 & 0 & 0.0 & 4 & 4.5 & 8 & 8.9 & 0 & 0.0 & \\
\hline \multirow[t]{2}{*}{ Q13_9 } & Disagree & 209 & 19 & 59.4 & 66 & 74.2 & 73 & 81.1 & 51 & 83.6 & 0.04 \\
\hline & Agree & 63 & 13 & 40.6 & 23 & 25.8 & 17 & 18.9 & 10 & 16.4 & \\
\hline \multirow[t]{2}{*}{ Q13_10 } & Disagree & 231 & 29 & 96.7 & 73 & 85.9 & 70 & 81.4 & 59 & 100.0 & 0.002 \\
\hline & Agree & 29 & 1 & 3.3 & 12 & 14.1 & 16 & 18.6 & 0 & 0.0 & \\
\hline
\end{tabular}

Table abbreviations: Q13-1: delay or cancellation of appointments (without prior notice), Q13-2: complaints about dental care cost, Q13-3: inability to meet financial obligations, Q13-4: non-compliance with your instructions or your advice, Q13-5: lack of cooperation during treatment, Q13-6: doubts about the treatment plan, Q13-7: excessive fear (fearful patient), Q13-8: lack of trust,Q13-9: inaccurate dental and medical history, Q13-10: lack of appreciation for your work, Q13-11: other (define).

Table 3: Differentiation in the percentages of agreement/disagreement on statements Q13 with respect to education (PhD/Master/Specialty).

\begin{tabular}{|c|c|c|c|c|c|c|c|}
\hline \multicolumn{8}{|c|}{ Master/PhD/Specialty } \\
\hline \multirow{2}{*}{\multicolumn{2}{|c|}{$\mathbf{N}$}} & \multirow{2}{*}{$\begin{array}{c}\text { Total } \\
\mathbf{n} \\
\end{array}$} & \multicolumn{2}{|c|}{ No } & \multicolumn{2}{|c|}{ Yes } & \multirow{2}{*}{ p } \\
\hline & & & $\%$ & $\mathbf{n}$ & $\%$ & & \\
\hline \multirow[t]{2}{*}{ Q13_1 } & Disagree & 122 & 83 & 39.9 & 122 & 43.6 & 0.035 \\
\hline & Agree & 158 & 125 & 60.1 & 158 & 56.4 & \\
\hline \multirow[t]{2}{*}{ Q13_2 } & Disagree & 116 & 82 & 39.2 & 116 & 41.4 & 0.201 \\
\hline & Agree & 164 & 127 & 60.8 & 164 & 58.6 & \\
\hline \multirow[t]{2}{*}{ Q13_3 } & Disagree & 114 & 75 & 35.9 & 114 & 40.7 & 0.005 \\
\hline & Agree & 166 & 134 & 64.1 & 166 & 59.3 & \\
\hline
\end{tabular}




\section{Advances in Dentistry \& Oral Health}

\begin{tabular}{|c|c|c|c|c|c|c|c|}
\hline Q13_4 & Disagree & 103 & 66 & 31.9 & 103 & 36.9 & 0.003 \\
\hline & Agree & 176 & 141 & 68.1 & 176 & 63.1 & \\
\hline \multirow{2}{*}{ Q13_5 } & Disagree & 214 & 155 & 74.5 & 214 & 76.4 & 0.201 \\
\hline & Agree & 66 & 53 & 25.5 & 66 & 23.6 & \\
\hline \multirow[t]{2}{*}{ Q13_6 } & Disagree & 255 & 187 & 91.7 & 255 & 93.4 & 0.046 \\
\hline & Agree & 18 & 17 & 8.3 & 18 & 6.6 & \\
\hline \multirow[t]{2}{*}{ Q13_7 } & Disagree & 145 & 108 & 51.9 & 145 & 51.8 & 0.938 \\
\hline & Agree & 135 & 100 & 48.1 & 135 & 48.2 & \\
\hline \multirow[t]{2}{*}{ Q13_8 } & Disagree & 255 & 190 & 95.5 & 255 & 95.5 & 0.970 \\
\hline & Agree & 12 & 9 & 4.5 & 12 & 4.5 & \\
\hline \multirow[t]{2}{*}{ Q13_9 } & Disagree & 209 & 149 & 73.4 & 209 & 76.8 & 0.021 \\
\hline & Agree & 63 & 54 & 26.6 & 63 & 23.2 & \\
\hline \multirow[t]{2}{*}{ Q13_10 } & Disagree & 231 & 171 & 89.1 & 231 & 88.8 & 0.852 \\
\hline & Agree & 29 & 21 & 10.9 & 29 & 11.2 & \\
\hline
\end{tabular}

Table abbreviations: Q13-1: delay or cancellation of appointments (without prior notice), Q13-2: complaints about dental care cost,Q13-3: inability to meet financial obligations, Q13-4: non-compliance with your instructions or your advice,Q13-5: lack of cooperation during treatment, Q13-6: doubts about the treatment plan, Q13-7: excessive fear (fearful patient), Q13-8: lack of trust, Q13-9: inaccurate dental and medical history, Q13-10: lack of appreciation for your work, Q13-11: other (define).

None of the statements in the first two parts of the questionnaire was affected by the working area of the respondents. On the contrary, statistically significant differences on agreement percentages appeared in the third and fourth part of the questionnaire. More specifically, as regards the lack of cooperation and the doubts about the treatment plan, dentists in rural areas agree by $46.2 \%$ and $20.5 \%$ respectively while those practicing in urban areas agree by $19.9 \%$ and $4.3 \%$, which is a statistically significant result $(\mathrm{p}<0.001)$. Accordingly, non-appreciation of work seems to affect more dentists in rural areas than those working in urban areas (24.3\%-9.0\%, p=0.006) (Table 4). As regards working hours, the agreement on the statement according to which dentists should fix patients' teeth rather than explain how dental problems can be prevented, seemed to be statistically different with respect to working hours $(\mathrm{p}=0.044)$. The largest percentage (8.3\%) appeared for those working more than 50 hours. The same group of dentists agreed on the statement that patients may not pay if they are dissatisfied with the dental work at a percentage of $32.4 \%(\mathrm{p}=0.015)$. They also feel fatigue and exhaustion at the end of the day $(\mathrm{p}<0.001)$, with lack of time for non-professional activities (p: 0.001) (Table 5).

Table 4: Differentiation in the percentages of agreement/disagreement on statements Q13 with respect to the area the dental practice is situated.

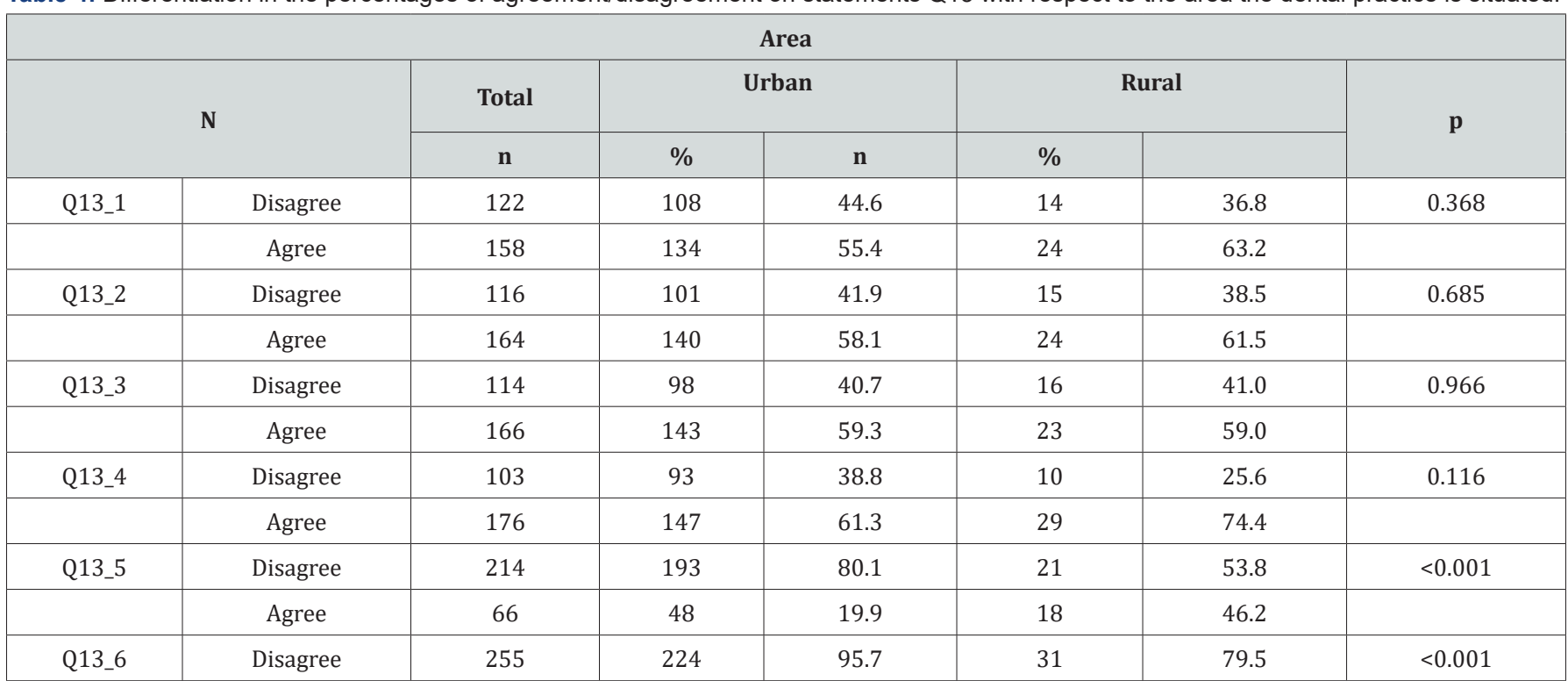




\section{Advances in Dentistry \& Oral Health}

\begin{tabular}{|c|c|c|c|c|c|c|c|}
\hline & Agree & 18 & 10 & 4.3 & 8 & 20.5 & \\
\hline \multirow[t]{2}{*}{ Q13_7 } & Disagree & 145 & 125 & 51.9 & 20 & 51.3 & 0.946 \\
\hline & Agree & 135 & 116 & 48.1 & 19 & 48.7 & \\
\hline \multirow[t]{2}{*}{ Q13_8 } & Disagree & 255 & 220 & 95.7 & 35 & 94.6 & 0.773 \\
\hline & Agree & 12 & 10 & 4.3 & 2 & 5.4 & \\
\hline \multirow[t]{2}{*}{ Q13_9 } & Disagree & 209 & 185 & 78.7 & 24 & 64.9 & 0.063 \\
\hline & Agree & 63 & 50 & 21.3 & 13 & 35.1 & \\
\hline \multirow[t]{2}{*}{ Q13_10 } & Disagree & 231 & 203 & 91.0 & 28 & 75.7 & 0.006 \\
\hline & Agree & 29 & 20 & 9.0 & 9 & 24.3 & \\
\hline
\end{tabular}

Table abbreviations: Q13-1: delay or cancellation of appointments (without prior notice), Q13-2: complaints about dental care cost, Q13-3: inability to meet financial obligations, Q13-4: non-compliance with your instructions or your advice, Q13-5: lack of cooperation during treatment, Q13-6: doubts about the treatment plan, Q13-7: excessive fear (fearful patient), Q13-8: lack of trust, Q13-9: inaccurate dental and medical history, Q13-10: lack of appreciation for your work, Q13-11: other (define).

Table 5: Differentiation in the percentages of agreement/disagreement on statements $Q 14$ with respect to working hours.

\begin{tabular}{|c|c|c|c|c|c|c|c|c|c|c|c|}
\hline \multicolumn{12}{|c|}{ Working hours } \\
\hline \multirow{2}{*}{\multicolumn{2}{|c|}{$\mathbf{N}$}} & \multirow{3}{*}{$\begin{array}{c}\text { Total } \\
\mathbf{n} \\
153\end{array}$} & \multicolumn{2}{|c|}{$<30$} & \multicolumn{2}{|c|}{$30-39$} & \multicolumn{2}{|c|}{$40-49$} & \multicolumn{2}{|c|}{$50+$} & \multirow{2}{*}{$\mathbf{p}$} \\
\hline & & & $\%$ & $\mathrm{n}$ & $\%$ & $\mathbf{n}$ & $\%$ & $\mathbf{n}$ & $\%$ & & \\
\hline \multirow[t]{2}{*}{ Q14_1 } & Disagree & & 27 & 56.3 & 53 & 58.2 & 50 & 48.1 & 23 & 63.9 & 0.311 \\
\hline & Agree & 126 & 21 & 43.8 & 38 & 41.8 & 54 & 51.9 & 13 & 36.1 & \\
\hline \multirow[t]{2}{*}{ Q14_2 } & Disagree & 222 & 38 & 80.9 & 73 & 81.1 & 82 & 78.8 & 29 & 82.9 & 0.955 \\
\hline & Agree & 54 & 9 & 19.1 & 17 & 18.9 & 22 & 21.2 & 6 & 17.1 & \\
\hline \multirow[t]{2}{*}{ Q14_3 } & Disagree & 151 & 26 & 54.2 & 45 & 50.0 & 60 & 57.7 & 20 & 57.1 & 0.738 \\
\hline & Agree & 126 & 22 & 45.8 & 45 & 50.0 & 44 & 42.3 & 15 & 42.9 & \\
\hline \multirow[t]{2}{*}{ Q14_4 } & Disagree & 237 & 40 & 93.0 & 78 & 91.8 & 90 & 89.1 & 29 & 85.3 & 0.644 \\
\hline & Agree & 26 & 3 & 7.0 & 7 & 8.2 & 11 & 10.9 & 5 & 14.7 & \\
\hline \multirow[t]{2}{*}{ Q14_5 } & Disagree & 93 & 24 & 50.0 & 37 & 41.1 & 27 & 25.7 & 5 & 13.9 & 0.001 \\
\hline & Agree & 186 & 24 & 50.0 & 53 & 58.9 & 78 & 74.3 & 31 & 86.1 & \\
\hline \multirow[t]{2}{*}{ Q14_6 } & Disagree & 80 & 25 & 52.1 & 31 & 34.4 & 20 & 19.0 & 4 & 11.1 & $<0.001$ \\
\hline & Agree & 199 & 23 & 47.9 & 59 & 65.6 & 85 & 81.0 & 32 & 88.9 & \\
\hline \multirow[t]{2}{*}{ Q14_7 } & Disagree & 143 & 27 & 56.3 & 43 & 48.3 & 56 & 53.8 & 17 & 48.6 & 0.769 \\
\hline & Agree & 133 & 21 & 43.8 & 46 & 51.7 & 48 & 46.2 & 18 & 51.4 & \\
\hline \multirow[t]{2}{*}{ Q14_8 } & Disagree & 79 & 15 & 31.9 & 23 & 25.6 & 28 & 26.7 & 13 & 36.1 & 0.604 \\
\hline & Agree & 199 & 32 & 68.1 & 67 & 74.4 & 77 & 73.3 & 23 & 63.9 & \\
\hline \multirow[t]{2}{*}{ Q14_9 } & Disagree & 233 & 41 & 93.2 & 75 & 90.4 & 86 & 87.8 & 31 & 96.9 & 0.427 \\
\hline & Agree & 24 & 3 & 6.8 & 8 & 9.6 & 12 & 12.2 & 1 & 3.1 & \\
\hline \multirow[t]{2}{*}{ Q14_10 } & Disagree & 213 & 37 & 82.2 & 70 & 83.3 & 82 & 79.6 & 24 & 70.6 & 0.454 \\
\hline & Agree & 53 & 8 & 17.8 & 14 & 16.7 & 21 & 20.4 & 10 & 29.4 & \\
\hline
\end{tabular}

Table abbreviations: Q14-1: failure to manage financial arrangements with patients, Q14-2: failure to organize and manage the dental practice as a business, Q14-3: financial distress in general, Q14-4: difficulty with respect to the lab, Q14-5: fatigue-exhaustion at the end of the day, Q14-6: lack of time for non-professional activities, Q14-7: failure to attend continuing education programs, Q14-8: low income in correlation with the time spent and the quality of your work, Q14-9: low acceptance by the social environment, Q14-10: loneliness, isolation, Q14-11: other(define).

\section{Discussion}

In the present study, an attempt was made to detect the most important problems dentists encounter in their profession.

\section{Relationship between dentists and patients-overall dentists' satisfaction}

Overall, dentists seemed to be satisfied with their relationship with their patients and their profession. As owners of private 
dental practices, they enjoyed autonomy while administrative and financial responsibilities did not seem to burden them. In addition, there is trust and good cooperation with their colleagues. Various studies are in agreement with the above while they state that administrative responsibilities seemed to be a burden $[3,7,9]$.

\section{Dentists challenges regarding financial issues-working hours}

Dentists agreed that their annual income is low, in relation to the working hours and the quality of care they offer. As regards long working hours, those were excessive and resulted in physical fatigue - exhaustion at the end of the day and lack of time for non-professional activities. Various studies agree with the above $[3,7,13]$.

\section{Long working hours and consequences}

Dentists who were working more than 50 hours per week, were likely to prefer to spend time exclusively on the clinical part of their work, rather than prevention. They also stated that patients should pay even if they were not satisfied. Long working hours usually aim at the economic growth of a dental practice. It results in emotional and physical fatigue while professionals adopt more mechanical roles, depriving their patients and themselves of the qualities of interaction and satisfaction [13].

\section{Relationship between dentists and their patients}

The majority of dentists agreed that they should answer their patients' questions and explain what the treatment plan involves, without forcing them to follow it. They also acknowledged patients' right to seek a second opinion. The patient feels more secure the dentist is earning recognition, probably indirect publicity, and satisfaction from the interaction with the patient $[5,14]$. it is suggested that patients retain only little of the information provided by the dentist during the dental work [15].

\section{Patients' satisfaction from dental care}

Patients often express complaints about previous dentists but rarely inform a dentist when they are dissatisfied with the treatment. It is likely that the effects of a non-suitable treatment appear at a later time, urging patients to change dentists. In other studies patients avoid expressing their complaints in writing, which depends on patient's personality $[16,17]$.

\section{General difficulties-everyday professional issues}

As regards the acceptance by the society, dentists felt accepted mostly in non-urban areas. In rural areas, dentists were concerned about lack of collaboration, doubts about the treatment plan and non-appreciation of their work. In various studies, dentists working in non-urban areas seem to cooperate better with the personnel and have more free time $[1,5]$.

\section{Dentists' differentiations due to gender}

No differentiations were observed either in terms of professional autonomy (individual professionals), working hours, revenues or location. In other studies, autonomy seems to concern more men than women while men draw more satisfaction from their work $[3,7,9,18,19]$. A differentiation was observed with respect to two issues. First, male dentists stated that they were unable to convince their patients to follow a certain treatment. Perhaps, women are more conciliatory having great persuasion power, thus being effective. Second, men agreed that patients may not pay if they are not satisfied with the treatment. Women are often stricter with the finances of their work, probably because they do not want to go over budget. In a study conducted by the American Association of Dentists, the findings were common [17].

\section{Dentists' differentiations due to age ( $>55$ years old)}

Older dentists were satisfied when dealing with their patients or the management of their dental practice. Probably if they had been dissatisfied, they would have changed profession. Furthermore, they did not seem to be bothered by a possible lack of medical-dental history. They have acquired great experience over the years, while in Greece there isn't an electronic medicaldental patient portfolio. They also believed that they should press patients to follow their instructions probably thinking they will have better chances of convincing them [20]. They stated that patients should not seek a second opinion about the suggested treatment, probably because they feel that their professional prestige is insulted $[1,2,5,3]$.

\section{Dentists' differentiations due to age (45-55years old)}

Middle-aged professionals stated that the most common problems were lack of trust from patients, non-appreciation of their work and failure to fulfill the financial-administrative requirements of their dental practice. We get the same findings in other studies too [5,21].

\section{Dentists' differentiations due to age $(<35)$}

Younger dentists didn't seem to be concerned with financial issues. A possible explanation is that they have the benefit of a business loan, or their financial situation is not strictly related to the income from the dental profession. They agreed that patients express complaints about previous dentists, comment on the dental work performed, inform if they are discontented and admit that choosing a dentist is often based on the treatment cost. Probably younger dentists are more willing to spend time talking with their patients, creating a climate of trust and trying to increase-maintain the clientele of the dental practice. Some studies agree with the above while others comment that younger dentists are more concerned with financial and administrative responsibilities [3,7,22-25,26].

\section{Dentists' everyday problems correlated with training level}

The dentists who hold a master's degree stated that the most frequent difficulties they encounter in their everyday practice is the delay or cancellation of appointments (without prior notice) 
and the expression of doubts about the treatment plan or even refusal to follow it. Probably cancellation of appointments is due to the economic recession who forced people turned to public dental care as they could not afford visiting private dental units. Moreover, they believe that they should not press their patients to follow their instructions. Issues such as inaccurate dental and medical history, financial-management issues and, finally, inability to receive continuing education also affect them negatively. This is in accordance with another Greek study [25].

\section{Conclusion}

As shown in the present study, dentists in Crete are generally contented with their profession and their relationship with their patients. Also, it is a common belief that they should inform patients about precaution measures. What concerns them most is the issue of long working hours in correlation with low revenues. The administrative responsibilities of the dental practice are a serious concern for younger professionals. Furthermore, both young dentists and dentists holding a master's degree are concerned with the lack of dental records. A workplace offering autonomy, competitive revenues, flexible working hours and minimum administrative burden, can increase the level of satisfaction drawn from work. Further research is required to determine whether the general financial conditions in a country affects this particular professional group, what does patients believe about dentists with respect to age, gender and education of both groups.

\section{References}

1. Luzzi L, Spencer AJ (2011) Job satisfaction of the oral health labour force in Australia. Aust Dent J 56(1): 23-32.

2. Starkel R, Guay A, Lo Sasso A, Vujicic M, Warren M (2015) Job Satisfaction among Dentists Varies by Type of Large Group Practice Setting. Health Policy Institute, American Dental Association.

3. Goetz K, Campbell SM, Broge B, Dörfer CE, Brodowski M, et al. (2012) The impact of intrinsic and extrinsic factors on the job satisfaction of dentists. Community Dent Oral Epidemiol 40: 474-80.

4. Chandrashekar J, Joe J, Bobby A (2017) Career Satisfaction among Dental Public Health Specialists in India-A Cross-sectional Survey. Journal of Clinical and Diagnostic Research 11: 1.

5. Wells A, Winter PA (1999) Influence of practice and personal characteristics on dental job satisfaction. J Dent Educ 63(1): 805-12.

6. Warr P, Cook J, Wall T (1979) Scales for the measurement of some work attitudes and aspects of psychological wellbeing. Journal of Occupational Psychology 52(2): 129-148.

7. Luzzi L, Spencer AJ, Jones K, Teusner D (2005) Job satisfaction of registered dental practitioners. Australian Dental Journal 50(3): 179185

8. Gallagher J, Patel R, Donaldson N, Wilson N (2007) The emerging dental workforce: why dentistry? A quantitative study of final year dental students' views on their professional career. BMC Oral Health 7: 7.
9. Lindmark U, Wagman P, Wåhlin C, Rolander B (2018) Workplace health in dental care-a salutogenic approach. Int J Dent Hyg 16(1): 103-113.

10. Moodley R, Naidoo S, Van Wyk J (2018) The prevalence of occupational health-related problems in dentistry: A review of the literature. Journal of Occupational Health 60: 1-16.

11. Ayers K, Thomson W, Newton J, Rich A (2008) Job stressors of New Zealand dentists and their coping strategies. Occupational Medicine 58: 275-281.

12. Demetriadis D, Konstantinidis R, Sarafidou G, Kontos D, Agrafiotis D, et al. (2008) The relationship between a dentist and patient. Beliefs and attitudes of patients visiting private dental practices in one municipality in Athens. Stomatologia 65: 46-54.

13. Cui X, Dunning DG, An N (2017) Satisfaction among early and midcareer dentists in a metropolitan dental hospital in China. J Healthc Leadersh 6: 35-45.

14. Röing M, Knutsson Holmström I (2012) Involving patients in treatment decisions-a delicate balancing act for Swedish dentists. Health Expectations 17(14): 500-510.

15. Misra S, Daly B, Dunne BS, Packer M, Millar B, et al. (2013) Dentistpatient communication: what do patients and dentists remember following a consultation? Implications for patient compliance. Patient Preference and Adherence 7: 543-549.

16. Sharma P (2017) The professional approach to handling complaints. BDJ 4: 17030.

17. (2016) American Cosmetic Dentistry. Male vs. Female Dentists: Differences in Treatment Methods.

18. Myers HL, Myers LB (2004) It's difficult being a dentist: Stress and health in the general dental practitioner. Br dent J 197(2): 89-93.

19. Marti C, Lanzon J, Edwards SP, Inglehart MR, Habil P (2017) Career and Professional Satisfaction of Oral and Maxillofacial Surgery Residents, Academic Surgeons, and Private Practitioners: Does Gender Matter? J Dent Educ 81(1): 74-86.

20. Charangowda BK (2010) Dental records: An overview. J Forensic Dent Sci 2: 5-10.

21. Grace M (2002) Are we older and wiser? Br Dent J 193(2): 61-68.

22. Baldwin PJ, Dodd M, Rennie JS (1999) Young dentists - Work, wealth, health and happiness. Br dent J 186(1): 30-36.

23. Barber M, Wiesen P, Arnold S, Taichman R, Taichman LS (2011) Perceptions of Business Skill Development by Graduates of the University of Michigan Dental School. J Dent Educ 75(4): 505-517.

24. Kobza J, Syrkiewicz-Świtała M (2018) Job satisfaction and its related factors among dentists: A cross-sectional study. Work 60(3): 357-363.

25. Yfantopoulos J, Oulis CJ, Yfantopoulos P, Papaioannou W (2014) SocioEconomic Inequalities in Oral Health: The Case of Greece. Health 6:2227-2235.

26. Al-Ansari A, Nazir MA (2018) Dentist's responses about the effectiveness of continuing education activities. Eur J Dent Educ 22(4): e737-e744. 
This work is licensed under Creative Commons Attribution 4.0 License

DOI: 10.19080/ADOH.2020.12.555838
Your next submission with Juniper Publishers will reach you the below assets

- Quality Editorial service

- Swift Peer Review

- Reprints availability

- E-prints Service

- Manuscript Podcast for convenient understanding

- Global attainment for your research

- Manuscript accessibility in different formats

( Pdf, E-pub, Full Text, Audio)

- Unceasing customer service

Track the below URL for one-step submission https://juniperpublishers.com/online-submission.php 